\title{
Made for China: Localizations of International Architecture in China, 2001-2018
}

\author{
Ben Parker
}

Overland Partners, Architects, San Antonio, Texas, USA

\section{Abstract}

To date, the story of architectural production in 21st century China has focused on institutions and actors in an ever-globalizing system of practice [1-4]. This worthy approach nevertheless obscures opposite yet equally significant trends, namely the localization of architectural products. Architectural practices are indeed becoming more global, and yet their work is-with notable exceptions-more frequently convicted of a necessity for localization, such that two buildings designed by an American firm, one in California and the other in Shanghai, should not be indistinguishable from each other. Thus, a more complete telling of this story demands an investigation of how the local and the national are represented materially in work that is, structurally, international. Through a close reading of several iconic buildings in China designed

Corresponding Author:

Ben Parker

benp@overlandpartners.com

Received: 15 March 2019

Accepted: 25 May 2019

Published: 20 November 2019

Publishing services provided by

Knowledge E

(c) Ben Parker. This article is

distributed under the terms of

the Creative Commons

Attribution License, which

permits unrestricted use and

redistribution provided that the

original author and source are credited.

Selection and Peer-review under the responsibility of the Architecture across Boundaries Conference Committee.
G OPEN ACCESS by international architects, this contribution proposes a framework for categorizing localization strategies. In addition, it investigates the origins of the localization imperative both in general and specific to China. These findings amplify architecture's cross-cultural vocabulary and improve the ability of architectural practices to consider the cultural sited-ness of their work not only in China but around the world.

Keywords: Representation, Iconic Architecture, Globalization, Localization, Glocal, Transculturation, Acculturation, Chinese Architecture, China

\section{Background}

For a profession intimately concerned with precision, whose members I have known to fret over the alignment of a light switch with an outlet down to the sixteenth of an inch, and who have seen in this anxiety a moral responsibility that encroaches upon the cosmic, architects all too often wield language with stupefying coarseness. In professional circles-that is, distinct from academic ones-well-crafted words can be regarded with suspicion as the masks behind which poor designs hide. Despite the efforts of generations of their academic teachers, working architects still constantly rely on gross signifiers of approval or disapproval to stumble through the design process: | like it, I hate it, it's beautiful, it's ugly, etc. While this direct language has emotional appeal that should not be overlooked in a profession whose success depends so deeply on 
relationships, it nevertheless impoverishes discussion and further entrenches the problematic boundary between academy and practice. Conversely, academic architectural language suffers from that painful upshot of cross-disciplinarity whereby terminology is imported haphazardly with neither a complete understanding of its original meaning nor a mature integration into the rest of architectural discourse. In its remoteness from the realities of architectural production, this convoluted terminology-including such recent examples as telemetry, syntaxis, and performativity-also contributes to the divide between the academy and the profession.

When practicing architects do employ more specific words in the design process, they most frequently use them as forces acting upon the architecture, rather than descriptors inherent to the architecture itself. For example: because there is an easement that runs through the southern end of the site, therefore the building is located on the northern end. Another: because the client had a limited budget, therefore the building is built out of simple materials. A third: because the predominant views are to the south, the building is arranged as a long bar so that each room has a southern view. This reductionist causeand-effect language, while not untrue in its description of the process, reduces a place's identity to the sum of decisions made about it. More importantly, by privileging process over product, this type of narrative ignores the end user, who neither knows nor cares what frustrations and victories were part of the creation of the building.

This division between designer and user is one of architecture's fundamental boundaries. It has resulted in misunderstandings that range from the amusing to the tragic. The failures of modernist urban planning lay fundamentally in the discrepancy between how people live and how designers think people live. Fortunately, this is a course from which architects are currently overcorrecting, most commonly by trying to involve end-users in the design process. Whether through surveys, charrettes, workshops, meetings, coffee appointments, or pop-up post-it note walls, architects-or, most often, people trained as architects who find that title too limiting-are becoming better listeners, which is an essential step in closing this gap between designer and user. However, it risks overshadowing an equal and opposite part of the dialogue, namely, the opportunity for architects to speak things into existence in a way that is user-focused, not designerfocused, which means product-focused rather than process-focused. As Alexandra Lange writes of the importance of product over process, "Owners, clients and residents come and go, but architecture lives on, acting a role in the life of the city and its citizens long after the original players are gone." [5] Just as architects are inviting citizens into the role of designer, designers themselves must go out and become citizens again, to articulate buildings from the perspective of experience. 
However, citizenship is a problematic concept when addressing a globalized architecture. It implies a sense of belonging, of rights and responsibilities, largely absent for architects in transnational practice, and sometimes absent for clients and end-users as well. The globalization of architecture creates another boundary, a sum of differences in geography, technology, nationality, language and culture. For architects, there is no dearth of boldness in crossing over this boundary, as the large number of foreigndesigned buildings in China attests. However, crossing over this cultural boundary highlights certain problems. The sheer size of the crevasse is demonstrated by the different epithets which attach to cross-cultural buildings. For example, the CCTV tower in Beijing, designed by Dutch firm OMA, was described in the New York Times as "the greatest work of architecture built in this century," [6] whereas most Chinese know it by its playfully pejorative nickname, the "big underpants (大裤衩)". What is significant is not that this building has a humorous sobriquet, but rather that the vast difference in assessment of the building between Western critic and Chinese public points to a fundamental difference of experience. Although they are looking at the same building, they are seeing different things, a difference revealed in the words used to describe the building. Indeed, each of the spheres mentioned above-designer, public, criticis delimited by its vocabulary. Cross-cultural architectural production only adds to the number of boundaries to be negotiated.

\section{Position}

By intentionally developing our vocabulary outwards towards others, rather than insulating ourselves through self-referential complexity on the part of academics; discoursearresting simplifications on the part of practitioners; cutting witticisms on the part of the public; and either reactionary xenophobia or perfunctory xenophilia on each side of a cultural divide, we can gain a clearer understanding of the boundaries in which our relationships are entangled, respecting those that are valuable and dissolving those that are not.

While this paper aspires to help bridge all aforementioned boundaries, it does so through the lens of cultural boundaries. More specifically, it looks at international architecture products in China and the phenomenon of their contextualization, of their "Chinese-ness." It seeks to create more specific answers to the question, "How is a building Chinese?" and in so doing clarify more broadly how designers of cross-cultural products contextualize their work. Crucially, it does so in a way that is accessible to architects and academics, the public and critics, Chinese and Westerners. In method, 
this paper privileges product over process for the reasons described above. Following John Berger, it looks carefully at built and proposed work to discern cultural meaning and the presence of cultural boundaries. This attentive looking is supplemented by sparing textual research when it helps to further elucidate the meanings and boundaries present in the tangible work.

\section{Imperative "Chinese-ness:" Contributing Factors}

Not all transnational architecture is as tightly enmeshed in a web of cultural boundaries as that practiced in $21^{s t}$ century China. The many factors that compel these buildings to project a strong cultural identity can be roughly categorized as historic, domestic, and international. These pressures lead architects-especially foreign architects, and especially architects designing iconic buildings-to employ 'localization strategies' that identify their buildings as Chinese.

Historically, after 1949, China adopted the Soviet principle that cultural products should be 'socialist in content, national in form.' This drove the creation of Socialist Classical buildings exhibiting iconography and ornamentation that was identifiable as Chinese, such as many of the Ten Great Buildings of 1959. This 'national form' has been a continuing driver in Chinese public architecture, visible in examples such as the 1996 Beijing West railway station. It's legacy is also evident in the project brief for the China National Grand Theater, in which Paul Andreu was asked to design a building "that people knew at first view to be a theater, a Chinese theater, and a theater beside Tiananmen [square]." [7] This historic context undergirds contemporary calls for a recognizably Chinese architecture.

The domestic factors emphasizing a recognizable Chinese identity include client desires and a milieu of government, academic, and public opinion. My own professional experience in China confirms the frequent request of clients, especially government clients, for buildings that are somehow Chinese. The reasons for this direction are complex, and should not be simplified down to a single government edict. National pride certainly plays a part, and a desire to counterbalance potential criticism about hiring an international design team. Many clients have complex, even potentially conflicting desires for their buildings: that they be futuristic and rooted in Chinese culture, worldclass and representative of their own city, etc.

Finally, the curiosity and interests of international actors also drives buildings towards a Chinese identity. Western architects have an enduring interest in an often-exoticized Chinese culture with which they are eager to engage for creative inspiration. This 
interest was already present in the Republican era, when architects like Henry Murphy used traditional motifs such as large, sloping roofs and lacquered columns to effect "a modern renaissance of [Chinese] architectural heritage" [8], and it continues with contemporary architects like John Van De Water and their studies of, among other things, Feng Shui and Daoism, in an attempt to "penetrate the Chinese surface" [9].

\section{Localization Strategies: Five Differentiations}

Having established that there is an imperative for architectural acculturation in $21^{s t}$ century transnational architecture in China, we now turn to the central question of this paper: just how is this localization imperative made manifest in built work? Specific, clear vocabulary drawn directly from a building's appearance can help us answer this question and reach across the cultural, professional, and linguistic boundaries highlighted in the introduction. The artist Robert Irwin has developed four categories for classifying art according to its physical context. Addressing mainly sculpture, he asserts that a work can be site dominant, site adjusted, site specific, or site determined/conditioned [10]. A similar system would be useful for categorizing how architects respond to cultural context. In this postmodern, pluralistic age, when an uncontrollable flow of everchanging information is constantly altering the conceptual landscape, designers must pick and choose what criteria will form the basis of their design. For foreign architects in China, this global situation is exacerbated by two factors: the immense speed at which China is currently building and developing, and the extensive and intricate history of the country which outsiders are always comparatively unfamiliar with. Thus, while borrowing from Irwin, this system of cultural response differs in that it looks not at the degree to which a work is affected by its context, but rather what element of context the work chooses to associate with. This in mind, I have identified five ways in which foreign architects respond to the Chinese situation: built adoption, cultural adoption, conceptual adoption, critical adoption, and experiential adoption.

Built adoption (建筑借用) references architecture found in China's history. This category includes the Chinese renaissance buildings of Henry Murphy and other missionary architects, where traditional Chinese roof forms were copied in modern concrete. It also embraces the postmodernism found later in the Shanghai Center and the Jin Mao tower. The Shanghai center takes certain elements of traditional Chinese building-dougong brackets, lacquered columns-and abstracts them in a different spatial arrangement and at a different scale. Similarly, the Jin Mao tower reinterprets the pagoda as a modern skyscraper of steel and glass. Built adoption could also reference more contemporary 
structures, such as if a hotel were designed to resemble a Mao-era factory. We can see this trend beginning to emerge in sensitive renovations of socialist-era buildings for a sophisticated public, such as the Alila Yangshuo hotel by Vector Architects, the Three Shadows Photography Center in Beijing by Ai Weiwei, and the Clock Museum of the Cultural Revolution in Chengdu by Liu Jiakun. Crucially, these projects are almost exclusively the work of domestic Chinese architects. In any case, built adoption involves accommodating contemporary requirements in a structure that references "traditional" architectural forms.
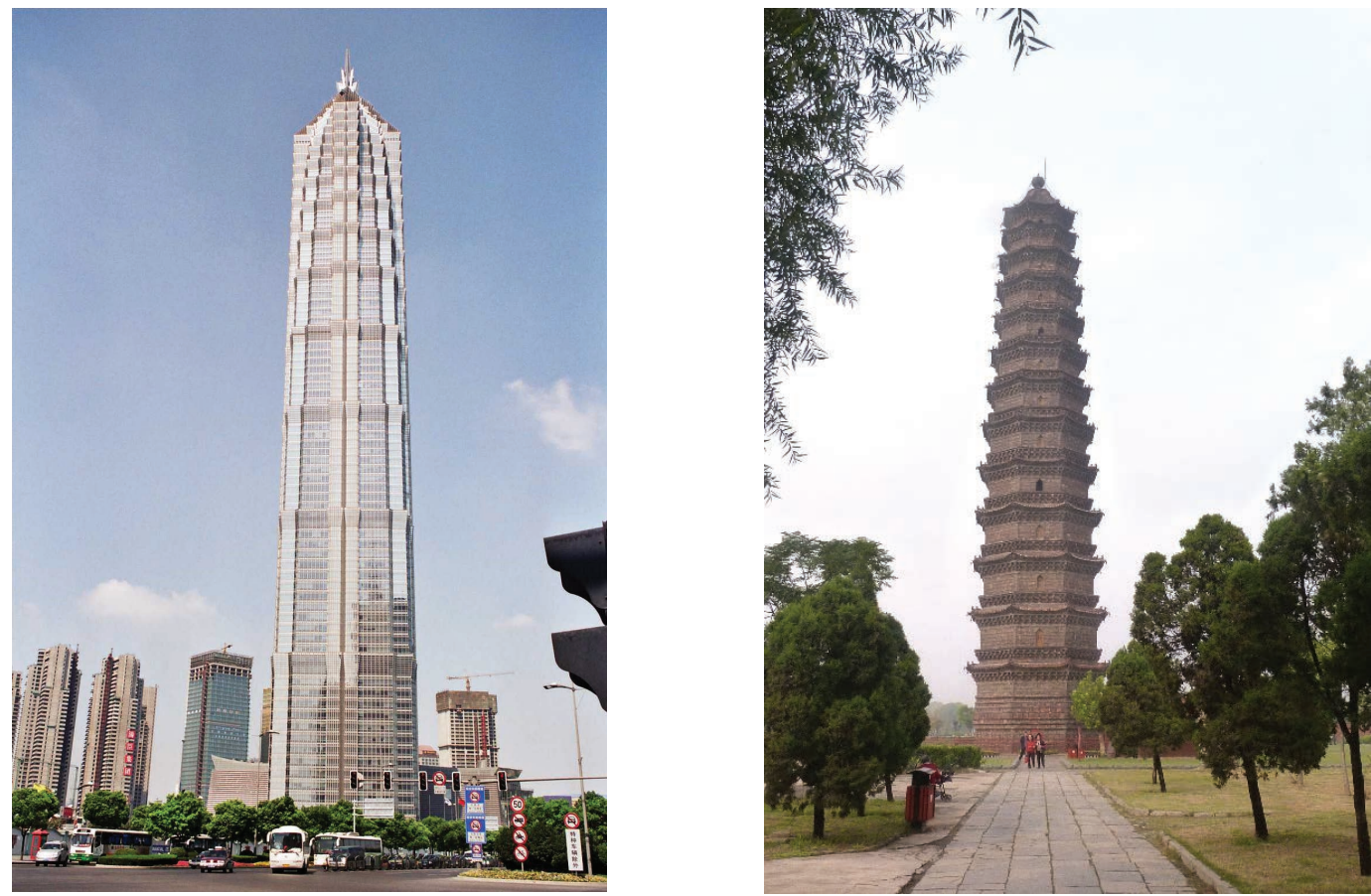

Figure 1: Images 1 \& 2: Built Adoption (建筑借用): the Jin Mao Tower and the Youguo Temple Iron Pagoda. Images courtesy of Wikimedia Commons.

Cultural adoption (文物借用) deals with form as well, but selects from a society's material culture rather than its buildings. This category continues to broaden as digital technology makes it possible to create a wider variety of forms on a large scale, and it seems a very popular choice for foreign architects. Herzog and de Meuron have remarked that their Olympic National Stadium (the Bird's Nest) resembles a Shang dynasty ritual vessel [11]. Other buildings have been designed to look like Chinese lanterns or traditional knots. The Ren building, so named for its unmistakable resemblance to the Chinese character for "people" (人), is a layered example of this type. In a video on the architect's website, the camera zooms around a digital model of the building as different symbols are overlaid on top of the form. First is 人, clearly visible in a frontal view of the building. This is followed by overlays of a triangle, 
square, circle, undulating line, and a rectangle, each shape emerging in succession as the camera moves around the building. Each of these shapes correlates to the five elements in Chinese cosmology: fire, earth, metal, water, and wood. Thus, the building is represented as a harmony of all five elements as well as a union of the mind and body (one leg of the 人 building is programmed for "mind" activities, such as office space, while the other is for "body" activities such as a hotel and gym). Implicit in this representation is the union between East and West. The mind-body dualism of Western philosophy is not as present in Chinese philosophy, which is more monist [12]. This slick piece of architectural marketing applies a veneer of syncretic philosophy to drive home the political point: a European architect is building in China in a culturally sensitive way.
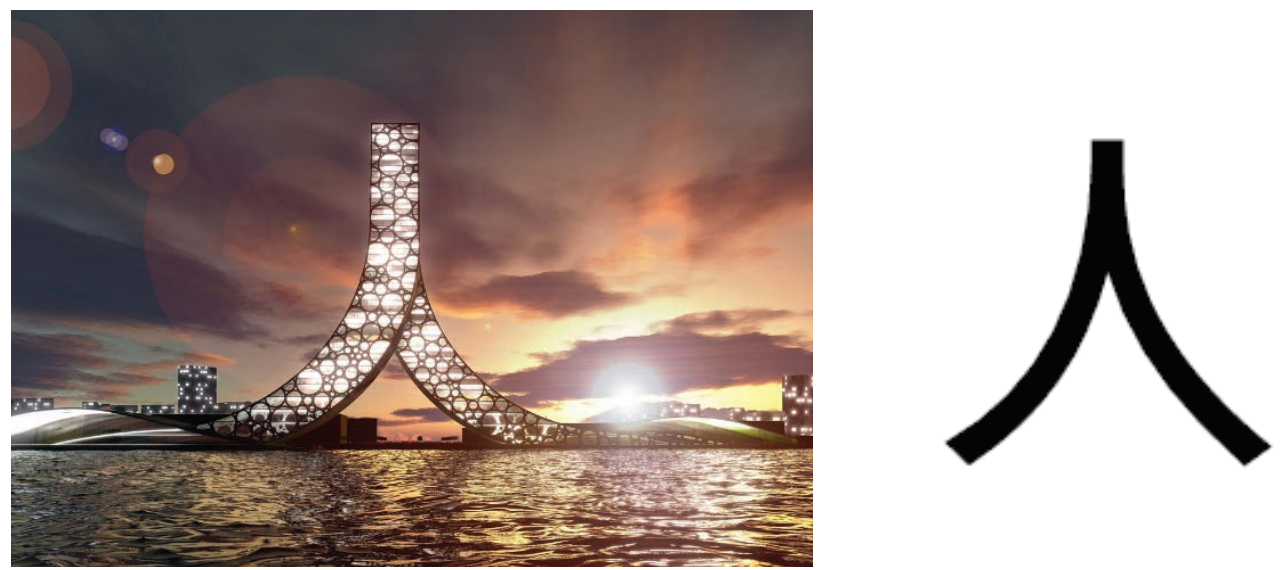

Figure 2: Images 3 \& 4: Cultural Adoption (文物借用): the Ren building and the Chinese character ren in Adobe Heiti Std B. Image source: http://projectjournal.org/wp-content/uploads/2012/07/ big_peoples_building.jpg.

The Dutch architect John van de Water describes a culturally adoptive project of exceptional literalism in his memoir about practicing in China, You Can't Change China, China Changes You: "During a discussion about old Beijing, the taxi driver told me that hundreds of years ago, at the time of the Ming Dynasty, a renowned silk market had existed at the site in question. I took this discovery, the site's particular history, as the motive for the design: hundreds of years of history were translated into an aluminum weave for the façade" [9]. This passage succinctly describes cultural adoption as an application of an object of material culture-silk-onto a building's form, and also illustrates the desire to link a building with a vanished past as a motivation for adopting this strategy.

Third, conceptual adoption (概念借用) does not deal directly with form. Instead, works in this category borrow concepts from Chinese philosophy, planning, or design and use them as frameworks to develop the project. Rarer than cultural adoption, likely because it requires a deeper cultural knowledge, one example is the New Nine Continents Park 

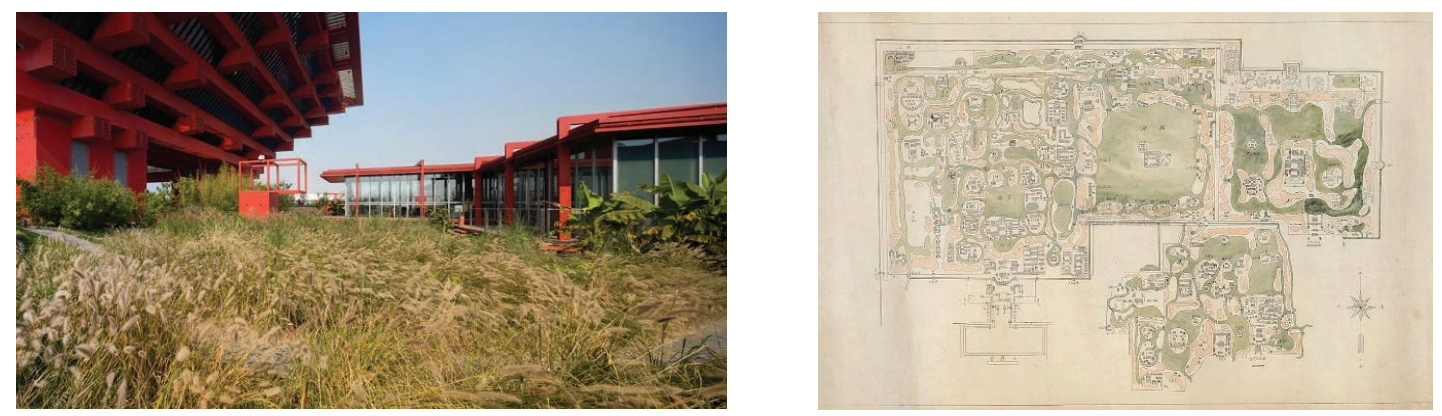

Figure 3: Images 5 \& 6: Conceptual Adoption (概念借用): The New Nine Continents Park and the Nine Continents Park. Image source: teamminus.com \& https://img1.artron.net/auction/2012/art501864/d/ art5018641261.jpg.

(新九州清宴), part of the Chinese pavilion at the 2010 Shanghai Expo. This project was developed jointly between an American landscape office, $L+A$, and a Chinese architectural office, TeamMinus. Although for consistency's sake I would have liked to find a project for the conceptual adoption category solely by a foreign architect, they are disappointingly rare. This park borrows from the Qing dynasty park of the same name, begun by the Qianlong emperor in the Summer Palace in the mid-eighteenth century. Itself a reaction to uncertainty following greater awareness of the widerparticularly European-world, the original park sought to unite the entire world in a single landscape in the emperor's domain. The new Nine Continents Park takes this notion and applies it to biomes, so that a farm, marsh, lake, mountain, forest, savanna, loess ravine, and desert ecology exist within one park (the ninth "continent" is the architectural pavilion). The design is particularly appropriate as part of the Chinese pavilion at the Shanghai Expo, an event on Chinese soil that showcased international variety yet united it in a single Chinese place. Landscape architecture and garden design may be more likely than architecture to utilize conceptual adoption in a Chinese context, because there are more foreign-language materials on Chinese gardens than on Chinese architecture. A hypothetical example of cultural adoption could be the spatial arrangement of a progression of courtyards. Deeply rooted in concepts of Chinese space, it is also flexible enough to accommodate modern programs of shopping, office work, multi-family housing, etc. The conceptual adoption method of cultural response requires a more nuanced knowledge of the culture one is responding to, because not every theory or framework would be appropriate for every project.

Fourth, there is critical adoption (批评借用). This category is a catch-all for projects that choose to respond formally to conditions of the Chinese city or building culture. While all buildings are conditional, formed as they are by a relationship among designer, client, contractor, user, and regulating body, critical buildings respond to these encounters intentionally. Steven Holl's Linked Hybrid would be an example, designed as a 
continuous flow of public space in reaction to the gated communities preferred by the growing Chinese middle class. The CCTV tower is also critically adoptive. Koolhaas' vision for the project was "to create ambiguity and complexity, so as to escape the constraints of the explicit" [13]. This stems partly from his own design ethos, but also from his belief that China has an unhealthy obsession with stability [14]. By housing China Central Television, one of the most stabilizing forces of Chinese society, inside an ambiguous structure, the CCTV tower is reacting to an institution that might rather have seen themselves in a towering skyscraper, keeping close watch on the city below. Wang Shu's reuse of traditional roof tiles in his contemporary facades is another example of critical adoption, a comment on the amount of destruction present in the modernization of Chinese cities.
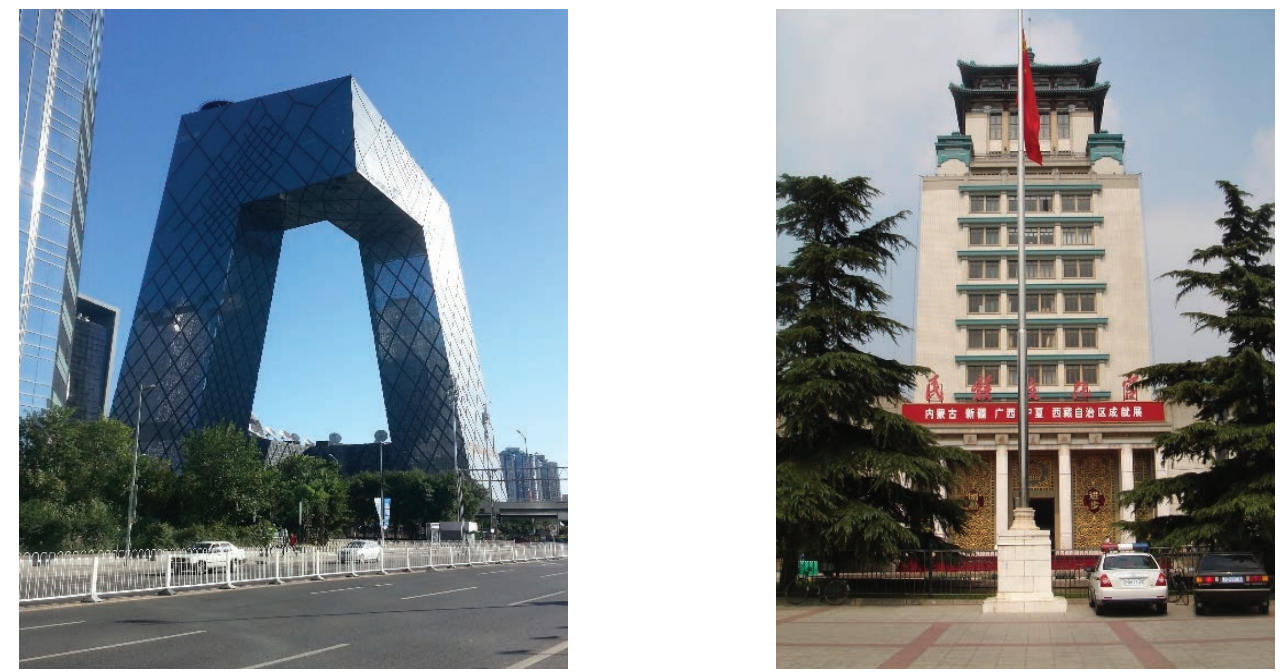

Figure 4: Images 7 \& 8: Critical Adoption (批评借用): deliberate contrast. The CCTV Tower and the Cultural Palace of Nationalities. Images courtesy of Wikimedia Commons.

Finally, experiential adoption (体验借用) utilizes memory of lived experience to recreate or comment upon culturally recognizable phenomena. It requires at least some embedded life experience in the target culture, and thus is, along with conceptual adoption, less commonly found in the work of foreign architects. One notable exception is the Guardian Arts Center in central Beijing by Buro Ole Scheeren. In an interview, Scheeren talks not only generally about the need to address history in such a sensitive site, but also about details of the city he has come to know personally. To him, the Guardian Arts Center matches "this granular, small scale texture the hutong has," while also complementing the phenomenological aspects of Beijing, which is "a very strong city...a very monumental city, [where] things are of large scale and things also have a very interesting sense of gravity, there's a weight to them, to the way in which they sit firmly on the ground" [15]. The embedding of these urban observations in the design for 
the Guardian Arts Center is an example of experiential adoption used to contextualize a project.

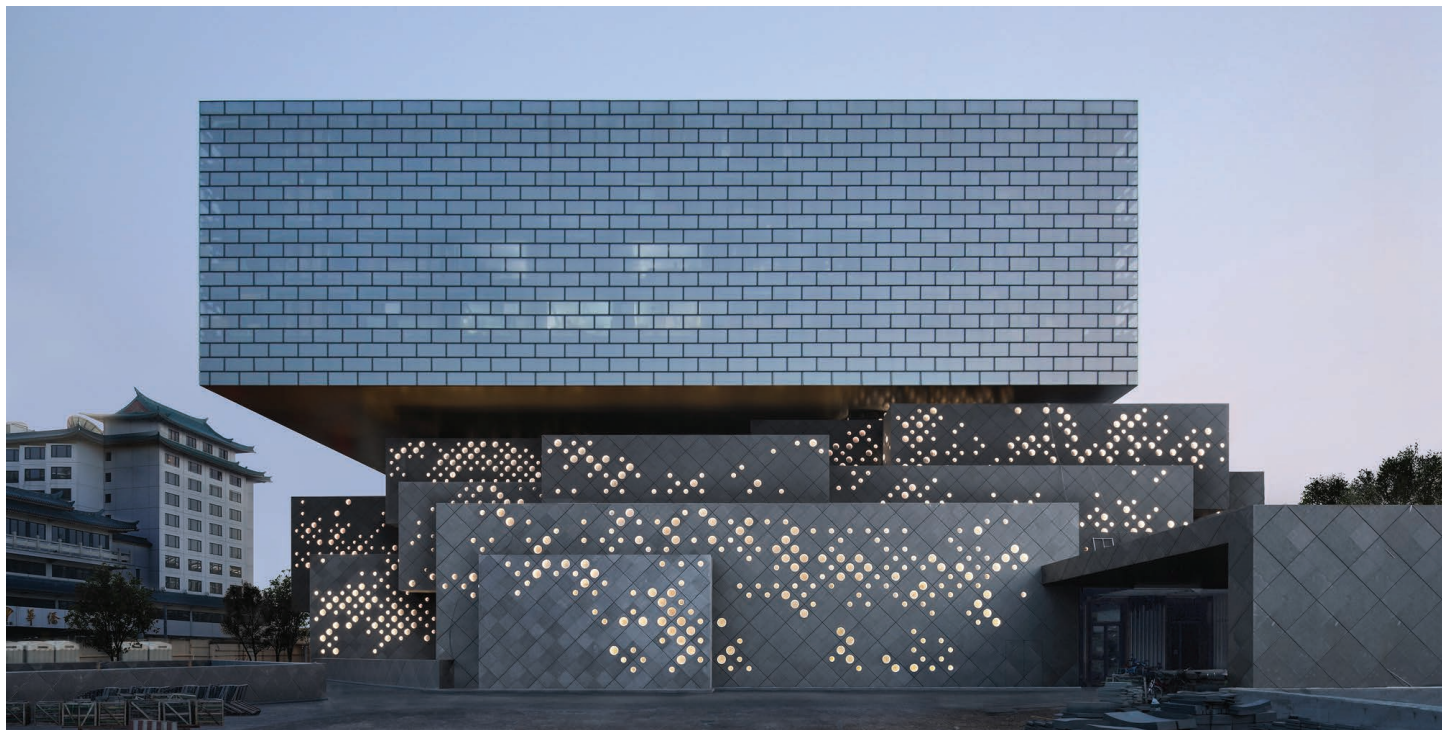

Figure 5: Image 9: Experiential Adoption (体验借用): The Guardian Arts Center. Photo by Iwan Baan.

Three caveats to this system of cultural response must be mentioned. First, the categories are not mutually exclusive. For example, grey brick could be used in a project because it is a traditional building material for China (built adoption), but also because it is a common material, readily available yet rejected by enterprising developers who crave steel-and-glass swoops that exude modernity (critical adoption).

Second, every architectural project is a complex endeavor with countless factors at play, many of them more important than cultural sensitivity. Often, the discussion of cultural fit occurs towards the end of the process, once the design has been published. Thus, the cultural dialog is often a mediation among client, designer, and public, rather than something inherent to the building itself. I think this could be the case with the Olympic Stadium (Bird's Nest) and the architects' remarks that liken it to a Shang dynasty bronze. Much of the discussion early on pertained to an operable roof that was removed from the project due to budgetary constraints; the now-familiar web of steel that gives the stadium its nickname was originally designed to screen the operations of this roof. While consideration of "Chinese culture" may have been an early interest for the architects, it was brought out later to appease a nationalist outcry from the public. This justification of form through cultural reference is difficult to decipher. It is hard to know whether the architect is post-rationalizing or expressing the honest intentions of the design. Thus, explanation of a cultural response-in any category but particularly cultural adoption-can feel like a palliative. The most successful projects 
are able to stand up to criticism with or without the use of metaphors, which can fall flat if misinterpreted.

The final condition is that architectural acculturation is not exclusive to designers outside of that culture. Chinese architects, too, address their own inheritance in the above ways, although they have different preferences for which methods they select. For example, cultural adoption is much less popular with Chinese architects, while conceptual adoption, critical adoption and experiential adoption are used much more frequently. The differences between how 'native' and 'foreign' architects utilize these adoptions is a topic for further study.

\section{Conclusion}

Architectural production will continue to globalize. While in the first two decades of the $21^{\text {st }}$ century it has been commonplace to find European and American architects working in China, India, and the Middle East, in the near future the hierarchies will flatten. With increasing normalcy, Chinese architects will be working in Africa, African architects will be working in South America, South American architects will be working in Europe, and everyone will basically be in everyone else's backyard. As this new state of transcultural practice emerges, it brings with it the threat of perpetual misrepresentation, so that all cultures-but especially one's own-become unrecognizable. The goal of this paper is, in a small way, to combat that threat by promoting a more specific vocabulary of contextualization, one that allows us to see not only 'if,' but also 'how' a building adopts a cultural identity. It is hoped that these common tools of communication will reach across the boundaries of academic and practitioner, public and critic, culture and culture.

\section{Conflict of Interest}

The author is employed by Overland Partners, Architects. The views expressed in this paper are solely his own.

\section{References}

[1] X. Ren, Building Globalization: Transnational Architecture Production in Urban China, Chicago, IL: University of Chicago Press, 2011. 
[2] D. Lu, "Architecture and Global Imaginations in China," The Journal of Architecture, vol. 12, no. 2, pp. 123-145, 2006.

[3] S. Chan, Writing In(to) Architecture: China's Architectural Design and Construction Since 1949, Hong Kong: East Slop Publishing, 2012.

[4] L. Xin, China, China...Western Architects and City Planners in China, Ostfildern, Germany: Hartje Cantz, 2008.

[5] A. Lange, "How to Be an Architecture Critic," Places Journal, March 2012. [Online]. Available: https://placesjournal.org/article/how-to-be-an-architecture-critic/. [Accessed 30 March 2019].

[6] N. Ouroussoff, "Koolhaas, Delirious in Beijing," The New York Times, 11 July 2011.

[7] W. Xu, "'Big Egg' Architect Teaches in Hangzhou," Hi Center (Hangzhou English Portal), 10 April 2012. [Online]. Available: http://www.hicenter.cn/columns_detail. asp?id=435260. [Accessed December 2014].

[8] J. Cody, Building in China: Henry K. Murphy's "Adaptive Architecture", Seattle: University of Washington Press, 2001.

[9] J. Van de Water, You Can't Change China, China Changes You, Rotterdam: 010 Publishers, 2012.

[10] R. Irwin, Being and Circumstance: Notes Toward a Conditional Art, Larkspur Landing, California: Lapis Press, 1985.

[11] S. Keller, "Bidden City," Artforum, pp. 137-142, Summer 2008.

[12] J. Rosker, "Epistemology in Chinese Philosophy," Winter 2014. [Online]. Available: http://plato.stanford.edu/archives/win2014/entries/chinese-epistemology. [Accessed 10 December 2014].

[13] R. Koolhaas, Interviewee, An Obsessive Compulsion towards the Spectacular. [Interview]. 18 July 2008.

[14] C. Dickey, "Architect Rem Koolhaas and the Next World Wonder," Newsweek, 16 July 2012.

[15] O. Scheeren, Interviewee, Buro Ole Scheeren Unveils Design for Guardian Arts Center in Beijing. [Interview]. 9 March 2015.

[16] "2nd Urbanism at Borders Global Conference; Borders Within Border: Fragmentation, Disposition, and Connection," 7 December 2018. [Online]. Available: http://eventos.uma.es/28457/detail/2nd-global-conference-urbanism-atborders.borders-within-border.-fragmentation-disposition-connecti.html. [Accessed 1 April 2019].

[17] A. J. Barnes, Museum Representations of Maoist China, Farnham, UK: Ashgate, 2014. 